\title{
دراسة تحليلية للأداء الفني لسباحة (50) متر زحف على البطن
}

أحمد محمد إبراهيم أحمد 1

1 باحث بقسم التدريب الرياضي و علوم الحركة كلية التربية الرياضية جامعة قناة السويس

\section{الملخص:}

ان التطور المذهل الذي نشهده في الآونة الأخيرة قد شمل كافة النواحي والمجالات، ومنها المجال الرياضي

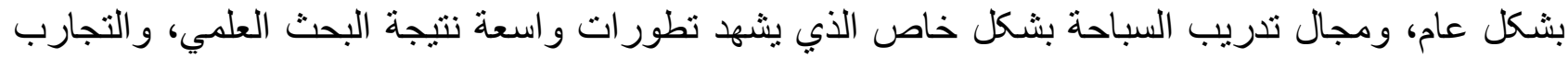
المتعددة، مما أدي الي تطور النتائج، والإنجازات بشكل مستمر، ت تكمن أهمية هذه الدراسة في أنها دراسة

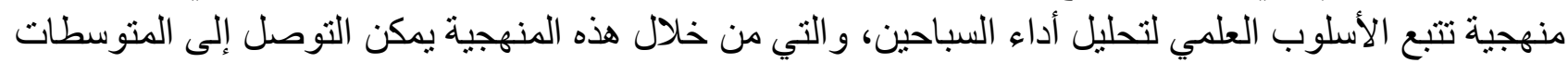

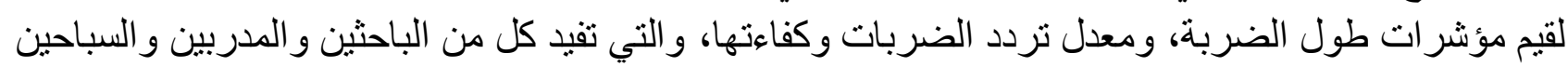
في العملية التدريبية. يتمثل مجتمع البحث الأصلي في السباحين الناشئين فئة (11) سنة المسجلين في الاتحاد المصري للسباحة، وتم اختيار عينة البحث بالطريقة العمدية من مجتمع البحث، وبلغ عددهم (20) سباح من مرحلة الناشئين فئة (11) سنة بنادي المقاولون العرب الرياضي. خلانل نتائج البحث وجد الباحث ان:

$$
\begin{aligned}
& \text { 1- منوسط الزمن لسباق (50) زحف علي البطن كان (36.52) . }
\end{aligned}
$$

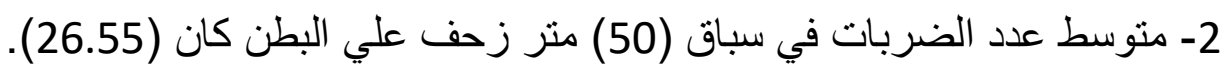

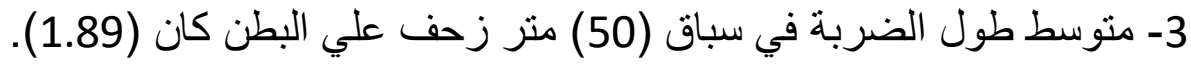

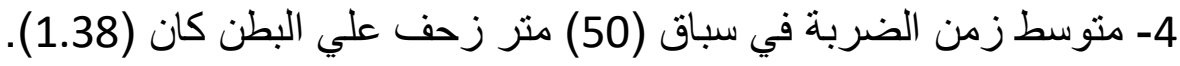

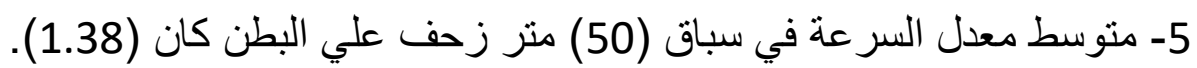

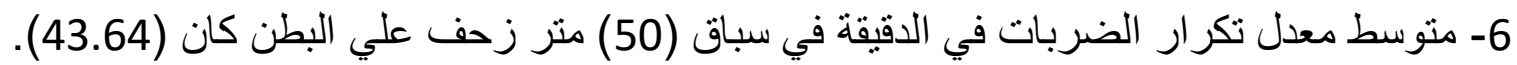

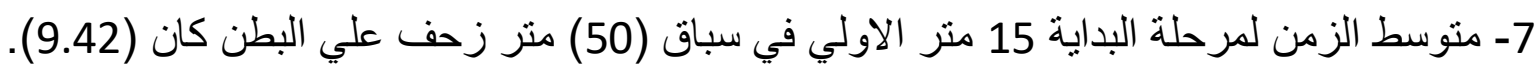

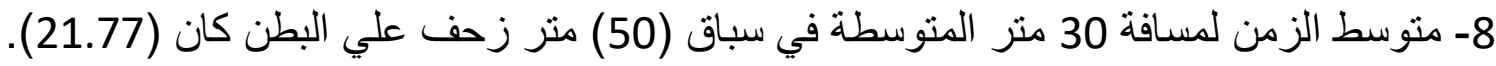

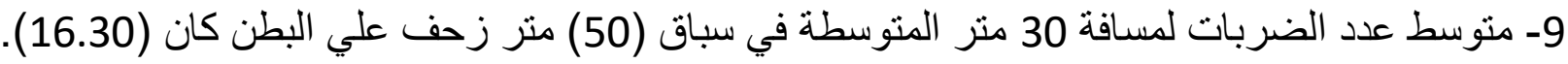
10- منوسط طول الضربة لمسافة 30 منر المتوسطة في سباق (50) منر زحف علي عني البطن كان (50) (1.85). 11- متوسط زمن الضربة لمسافة 30 منر المتوسطة في سباق (50) منر زحف عن علي البطن كان (50) (1.34). 12- منوسط معدل السرعة لمسافة 30 منر المنوسطة في سباق (50) منر زحف من علي البطن كان (1.39).

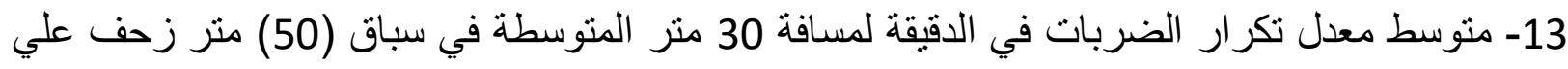

$$
\text { البطن كان (15.02). (15.02). }
$$

الكلمات الافتتاحية: در اسة تحليلية، (50) منر ، سباحة، زحف على البطن 
إن التطور المذهل الذي نشهده في الآونة الأخيرة قد شمل كافة النواحي والمجالات، ومنها المجال الرياضي بشكل عام، ومجال تدريب السباحة بشكل خاص الذي يشهد تطورات واسعة نتيجة البحث العلمي، والتجارب المتعددة؛ مما أدي الي تطور النتائج، و الإنجاز ات بشكل مستمر.

ويعتمد تحقيق المستويات الرياضية المتقدمة على مدى القدرة علي النجاح في تطبيق العلوم الطبيعية، و الانسانية بما تخدم تطوير استعدادات و إمكانات الرياضي وتتمية قدراته، ويعتبر التحليل الحركي أحد الركائز الهامة لرفع المستوي الرياضي للسباح باكتساب الأداء الفني، و المهاري الصحيح لارتفاع مستوى الإنجاز ، وتعتبر عملية التدريب الرياضي في السباحة أحد مجالات البحث العلمي التي تهدف للارتقاء بقدرات اللاعبين من الجانب البدني و المهاري لأقصى ما تسمح به قدر اتهم، فكلّ من الجانبين مكمل للأخر وتكاملهما معًا يؤدي لتحقيق الهدف من العملية التدريبية، وهذا التر ابط بين الجانبين البدني و المهارى أدى لضرورة وجود أداة تساعد في جمع بيانات شاملة عن الأداء المهارى، وتمثلت هذه الأداة في عملية التحليل الحركي الذي يعتبر أداة للتعامل مع كل المهام المرتبطة بالأداء المهاري؛ حيث بساعد في در اسة الأداء البشرى، والاستفادة من العلوم المرتبطة بالإنسان من خلال وصف المهارة، ووضع الحلول المناسبة لعلاج أخطاء الأداء و الوقاية من الإصابات. (7: 23-24) ويثنير عادل عبد البصير (1998م) إلى أن الدراسة الموضو عية للمهارة الحركية تساهم في إيجاد الأسس، و القو اعد، و الشروط المناسبة، و أفضل، و أنسب، وأعلى أداء مهاري ممكن. (8: 13) وكثيرًا ما يو اجه مدربي السباحة أخطاء كثيرة متعلقة بطرق الأداء الفنية، ومن خلال عمليات التحليل الحركي لأداء السباح يمكن التعرف على مواطن القوة، أو الضعف في الأداء ثم السعي إلى تحديد الأخطاء وطرق علاجها، بما يمكننا من فهم طبيعة الأداء الحركي للسباحين خلال سباحة المسافات المختلفة وفقًا لطرق الأداء المعينة

$$
\text { ومهار ات السباحة. (16: }
$$

ويتطلب الأداء في رياضة المستويات العليا تحسنًا وتطورًا مستمرًا في منظومة العملية التدريبية، وما تتضمنه من تمارين وبر امج حديثة ومتقدمة، وأن التقدم الحاصل في رياضة السباحة منذ بداية الألعاب الأولمبية الحديثة ما هو إلا نتاج لتطور التكنيك في كل نوع من أنواع السباحة ، و الطرق التدريبة المستخدمة خلال بر امج الموسم التدريبي للسباحة ، ومن الثائع بين السباحين والمدربين محاولة تقليد التكنيك الخاص بهؤلاء السباحين الذين حصلو ا على ميداليات أولمبية، أو حطمو أرقاما عالمية، وهذا يوضح مدى أهمية الأداء الفني الدقيق بشكل أكثر 
اقتصاديه لتحقيق أفضل الإنجاز ات، حيث اتجهت الأبحاث العلمية في الوقت الحالي إلى در اسة مكونات التكنيكات المختلفة، وإيجاد التفسير ات العلمية الدقيقة للتعرف إلى الفروق بين هذه التكنيكات و أيهما أفضل من الآخر، ولكن تتوع المتغير ات الو اقعة في هذه العملية وتثابكها صعّب مهام العلماء و الباحثين. (14: 2-3) ويرى أبو العلا عبد القتاح، (11 + r م) أنه إذا كانت سرعة السباح تتأثر بكفاءة الجهاز العصبي، ونظم إنتاج الطاقة من الناحية الفسيولوجية، وكذلك بمستوي القوى العظمي والقوة المميزة بالسرعة والمرونة من الناحية البدنية، فإنها من الناحية الفنية تتأثر بكفاءة الضربات بكل من طول الضربة، ومعدل الضربات؛ كما ترجع أهمية التعرف على معدل الضربات إلى أنها تعطي مؤشرًا لكل من الإيقاع و التوقيت، حيث للتوقيت أهمية كبيرة، وخصوصًا في سباحة الصدر، كما أن معدل الضربات البطيء سوف يؤثر سلبًا على التوقيت الخاص لكل سباحة، بينما معدل الضربات السريع جدًا سوف يجعل الضربات قصبرة، وبالتالي يؤثر على طول الضربة. (2: 56) ويثير محمد علي القط (2004 م) إلى أن قياس معدل الضربات وطولها قد أصبح من العمليات الثائعة في سباحة المنافسات، حيث تثير التقارير التي طغت على معظم المسابقات الرئيسية العالمية أنها تشمل بثكل روتيني على حسابات معدل ضربات الذر اعين وطولها وكذلك السرعة، بالإضافة إلى زمن أجز اء السباق، ويتم ذلك من خلال استخدام أجززة ومعدات حديثة، حيث يتم وضع خمس كاميرات فيديو أو أكثر بطول حمام السباحة وفي زو ايا مختلفة؛ وذلك لتسجيل السباق، وبالتالي يمكن تحليل السباق من زوايا مختلفة خلال أجز اء السباق المختلفة، فمعدل الضربات يرجع إلى معدل دورات الذراعين في السباحة أثناء السباقات، ويمكن تفسيرها وفقًا لعدد الضربات التي تؤديها الذر اعين في السباحة اثناء السباقات، ويمكن تفسيرها وفقًا لعدد الضربات التي تؤديها الذر اعين في الدقيقة (دورة/دقيقة) أو الزمن، و على ذلك فإن هذين العاملين هامان في تقييم أداء السباحين، وتحديد عو امل تطوير السرعة من خلالهما. (13: 146) و أظهرت الدر اسات أن تردد (معدل) الضربة، وما يعبر عنه بعدد الضربات بالدقيقة، يعد عنصرًا مهمًا جدًا لإنجاز زمن أفضل في المنافسات؛ حيث يستطيع سباحو المستويات العليا الوصول لترددات جيدة عالية بقدر الوصول لسرعات عالية عند ترددات منخفضة. (14: 4) ويوضح أبو العلا عبد الفتاح (1994م) النو احي الفنية والخططية: بأنها قدرة السباح على التو افق بين مكونات السباق المختلفة اعتبارًا من نمطي البدء، و السباحة، و الدوران، وكيفية التركيز على المكونات الأولية، و المركبة لكل من هذه العناصر . وقد توصلت بعض الدر اسات أن البدء له تأثثر كبير على تحسن المستوى الرقمي فى كافة 
الدسابقات، فالبدء الجيد يؤدى إلى تحسن رقم الـ 50 م الأولى ما بين 1: 2 ثانية دقارنة بنفس الرقم لنفس المسافة بدون البدء، و لابد من ملاحظة العلاقة بين البدء، و الدوران، وزمن الأجزاء حتى يمكن للسباحين تقسيم الأداء الفني وتحسين المستوى الرقمي. (1: 55)

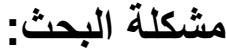

يرتبط تحسين مستوي الإنجاز الرقمي في السباحة علي العديد من العو امل المنداخلة، و التي يمكن من خلال

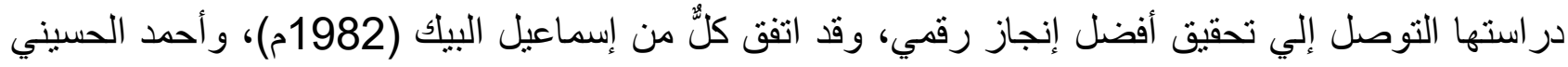
(1984م) على أن الإرتقاء بمستوي السباحين يرجع في الحقيقة إلي استغلال بعض العوامل التي تعتبر بمثابة مقومات أساسية يمكن عن طريقها التقام بنتائج السباحين، وأن الضبط الأمثل للأداء سواء أواء أكان فنيًا أو خططيًا يؤثر في توزيع الجها و العبء الواقع علي الأجهزة الحيوية؛ مما يحقق مبدأ اقتصادية الجهد، ويؤدي إلي رفع لهن مستوي الإنجاز الرياضي. (4)، (3) كما يرى أبو العلا عبد الفتاح (1994م) أن الأداء الفني و الخططي من أهم العو امل المؤثرة في تطوير النتائج الرياضية؛ ولذلك فإن عملية تحسين النواحي الفنية والخططية تسنمر خلال جميع مر احل إعداد السباح خلال

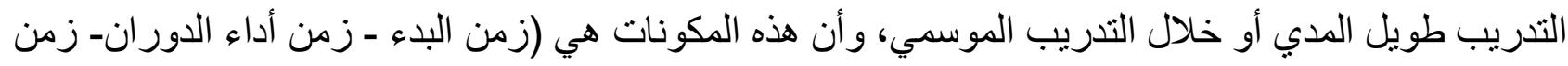

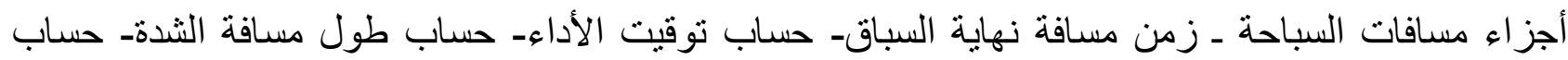
متوسط سرعة السباحةـ حساب الزمن الكلي لمسافة السباق، وعلاقته بأزمنة الأجز اء الأخرى، ومؤشرات الأداء

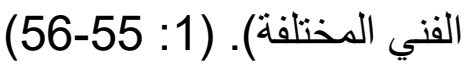

ويشير ماجليشكو Maglishc (2003م) إلى أن قياس معدلات تردد الضربات وطولها من العطليات الثنائعة

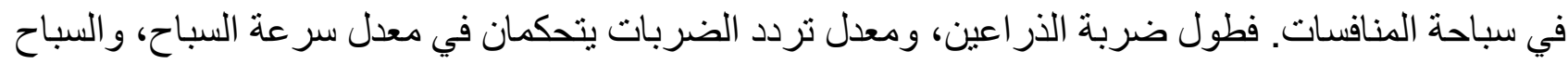

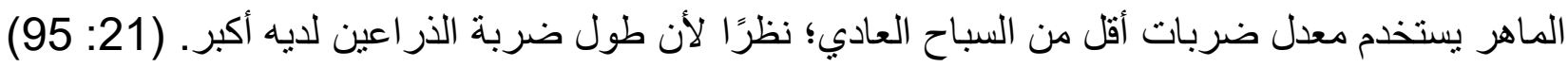
ويذكر عصام حلمى (1997م) أن زمن السباحة يساوى مجموع الأزمنة المأخوذة للبدء و الضربات و الدوران.

ويؤكد شوبرت Schubert (1990م) على أن هنالك ثلاثة عو امل هامة جداً يجب أن توضع في الاعتبار في التدريب لسباحي المسافات القصيرة و المتوسطة، وهي البدء و الدوران و إنهاء السباق، وير اعى في التدريب 
أن يكون مطابقة تماماً لما سوف يتم أثناء السباقات الحقيقية، وأن كل وحدة من الأجزاء السابقة تتطلب تركيزاً

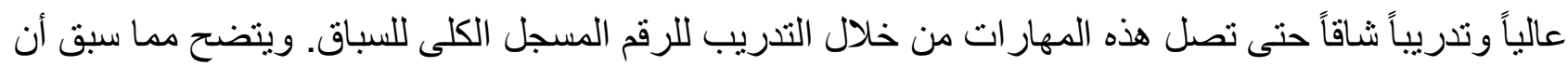
مكونات الأداء الفني للسباق ذات أهمية في تحقيق أزمنة أفضل في السباحة. (22: 228-244) و هذا هو الذي دفع الباحث لإجراء هذه الدراسة التحليلية للوقوف على مواطن الضعف، والقوة في الأداء، ووضع توصيات للمدربين تساعد في الحفاظ على قاعدة النانشئين، و الوصول بهم للعالمبة، و الأولمبية في رياضة ولهن السباحة.

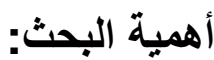

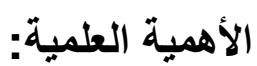

تكمن أهمية هذه الدر اسة في أنها در اسة هنهجية تتبع الأسلوب العلمي لتحليل أداء السباحين، والتي من خلال هذه المنهجية يمكن التوصل إلى المتوسطات لقيم مؤشرات طول الضربة، ومعدل تردد الضربات وكفاءتها، و التي تفيد كل من الباحثين و المدربين و السباحين في العملية التدريبية.

الأهمية التطبيقية:

تحاول الدراسة تقديم إسهام تطبيقي للمدربين والسباحين على حد سواء للتغلب على مشاكل كفاءة التكنيك

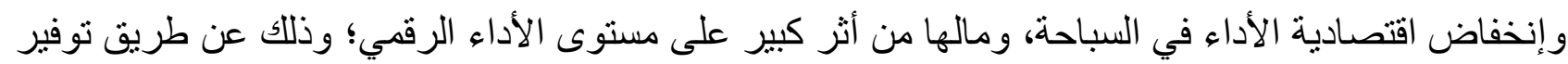
قاعدة بيانات رقمية من خلال الدراسة التحليلية، كما أن هذه الدراسة تعد محاولة جادة لتحسين مفاهيم الأداء الصحيح الأكثر فعالية نحو تطوير الواقع الرقمي للأداء في السباحة من خلال معرفة مكونات الأداء الفني للسباحات الأربعة، وتأثثر ها على المستوى الرقمي لنوع لنه السباحة.

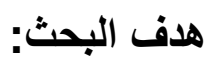

يهدف البحث إلى تحليل الأداء الفني لسباحة الزحف على البطن في سباق (50) متر لفئة (11) سنة. 
في ضوء هدف البحث تم وضع التساؤلات الآتية: 1- ما هي القيم الكمية لمتوسط متغيرات الأداء الفني (الأزمنة - طول الضربة ـ معدل الضربات - زمن الضربة) خلال مرحلة المسافة الكلية لسباق (50) منر زحف على البطن؟ 2- ما هي القيم الكمية لمتوسط متغير ات الأداء الفني (الأزمنة ـ طول الضربة ـ معدل الضربات - زمن الضربة) خلال مرحلة البداية 15 متر الاولي في سباق (50) متر زحف على البطن؟ 3- ما هي القيم الكمية لمتوسط متغير ات الأداء الفني (الأزمنة ـ طول الضربة ـ معدل الضربات - زمن الضربة) خلال مسافة 30 متر المتوسطة في سباق (50) متر زحف على البطن؟ 4- ماهي القيم الكمية لمتوسط متغير ات الأداء الفني (الأزمنة ـ طول الضربة ـ معدل الضربات - زمن الضربة) خلال مرحلة النهاية 5 منر الاخيرة في سباق (50) منر زحف على البطن؟

إجراعات البحث: | (إث: منهج البحث:

استخدم الباحث المنهج الوصفي بالأسلوب المسحي لمناسبته لطبيعة البحث.

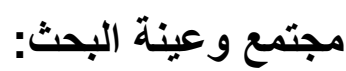

يتمثل مجتمع البحث الأصلي في السباحين الناثنئين فئة (11) سنة المسجلين في الاتحاد المصري للسباحة، وتم اختيار عينة البحث بالطريقة العمدية من مجتمع البحث، وبلغ عددهم (20) سباح من مرحلة الناثنين فئة (11) سنة بنادي المقاولون العرب الرياضي طبقًا للثروط التالية: - مسجلين في الاتحاد المصري للسباحة. - الانتظام في التدريب. ـ المشاركة في بطو لات الجمهورية للسباحة. 
جدول (1) يوضح المتوسط الحسابي، والانحر اف المعياري، ومعامل الالتواء لبعض المتغير ات لعينة البحث.

جدول (1)

المتوسط الحسابي، والانحراف المعياري، ومعامل الالتواء لعينة البحث (ن=20)

\begin{tabular}{|c|c|c|c|c|c|}
\hline الالتواء & الانحراف المعاري & الوسبط & المتوسط الحسابي & وحدة القياس & المتغيرات \\
\hline 0.35 & 1.74 & 141.00 & 141,20 & سم & الطول \\
\hline-0.38 & 1.59 & 36.50 & 36.30 & كجم & الوزن \\
\hline 0.45 & 1.99 & 39.50 & 39,80 & شهر & العمر التدريبي \\
\hline 0.45 & 1.99 & 135.50 & 135.80 & شهر & العمر الزمني \\
\hline-1.05 & 2.73 & 37.48 & 36.52 & ثنانية & زمن البطن 50م زحف \\
\hline
\end{tabular}

يتضح من الجدول (1) أن المنوسط الحسابي لطول أفراد العينة هو (141.2)، والمتوسط الحسابي للوزن هو (36.3)، و المتوسط الحسابي للعمر الزمني هو(135)، والمتوسط الحسابي للعمر التدريبي (39.8)، و المتوسط الحسابي لزمن 50 منر زحف علي البطن (36.52).

كما يتضح من الجدول (1) أن معامل الالتو اء لمتغيرات (الطول ـ الوزن ـ العمر التدريبي ـ العمر الزمني

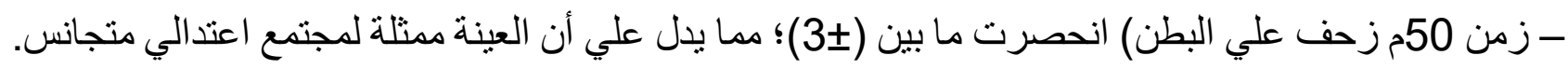
مجالات البحث: أولًا: المجال الزمني: في الفترة من 2021/4/4م الي 2021/4/13م. ثنانيًا: المجال المكاني: حمام السباحة الأوليمبي لنادي المقاولون العرب الرياضي. 
ثالثًا: المجال البشري: السباحين الناشئين فئة (11) سنة بنادي المقاولون العرب الرياضي المسجلين بالاتحاد المصري اللسباحة.

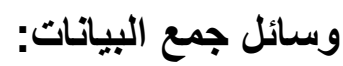
- المر اجع العلمية، والدراسات المرتبطة، وشبكة المعلومات (الانترنت). الأجزةة، والأدوات المستخدمة في البحث: - جهاز الرستاميتر لقياس الطول بالسنتيمتر، و الوزن بالكيلو جرام. - ساعة إيقاف رقمية (100/1) من الثانية. - حمام سباحة أوليمبي 50 متر الخاص بنادي المقاولون العرب الرياضي. - مريط قياس طوله 25 متر.

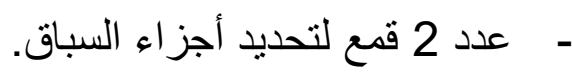

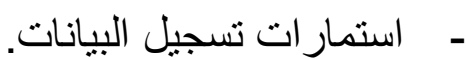

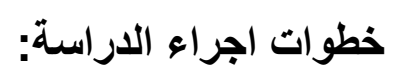$$
\text { - تحديد المقاييس، والاختبار ات المستخدمة في البحث. }
$$$$
\text { - تحديد الأدوات، و الأجززة المستخدمة في البحث. }
$$

- اختيار المساعدين: قام الباحث باختيار عدد 4 مساعدين من خريجي كليات التربية الرياضية المهتمين بتدريب السباحة و التحليل الحركي، وتدريبهج على إجر اء القياسات، وتسجيل البيانات، وتوزيع الأدوار

$$
\text { عليهم. }
$$

- - م إجراء الدراسة الاستطلاعية.

- الإجر اءات، و الجدول الزمني لإجر اء الدراسة الأساسية للبحث.

- - إعداد البيانات للمعالجة الإحصائية. 


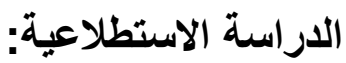

قام الباحث بإجراء الدراسة الاسنطلاعية على (8) سباحين من نادي المقاولون العرب من مجتمع البحث

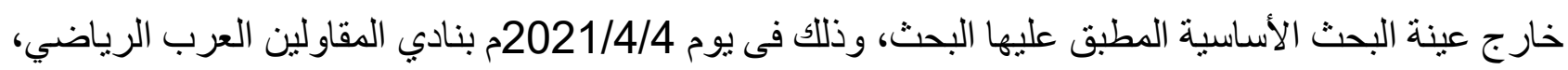

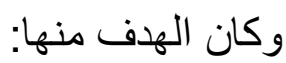

\section{- التأكد من صلاحية وكفاءة جميع أدوات و أجهزة القياس المستخدمة.} - - تحديد مسافات أجز اء السباق المختلفة بعلامات إرشادية بعد قياس المسافات و التأكد من دقتها. - تدريب المساعدين على كيفية تنفيذ القياسات المستخدمة. - التعرف على أية مشكلات مفاجئة، قد تعوق عملية إجراء الدراسة الاساسية. - التعرف على مدي مناسبة أزمنة ومو اعبد القياس للسباحين. - اكتثاف نواحي القصور في القياسات وطبيعة العينة. وقد أسفرت نتائج الاراسة الاستطلاعية عن: - صلاحية القياسات، وجميع ادوات وأجهزة القياس المستخدمة. - التأكد من كفاءة المساعدين في تطبيق جميع القياسات. - مناسبة مو اعيد وأزمنة القياس للسباحين. - - مديد مسافات أجز اء السباق بدقة. - تصميم رسم كروكي توضيحي لسير تطبيق الدراسة الأساسية موضحًا فيه: (اتجاه خط سير السباحة وفقًا لعدد المتغيرات ـ أماكن نواجد الباحث و المساعدين ــ أماكن الكاميرات)

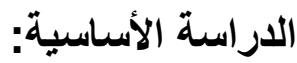

أولاً: تاريخ إجراء الاراسة الأساسية

تم إجر اء الدراسة الأساسية بتاريخ 2021/4/13م علي عينة البحث

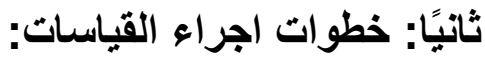

- - تم إجر اء الإحماء لمدة (30) دقيقة مقسمين (10) دقائق أرضي (20) دقيقة مائي. - ثم إبلاغ السباحين بأداء أقصى مجهود لتحقيق أفضل زمن ممكن. 
- ومن خلال أداء السباحين لسباحة الزحف علي البطن، قام المساعدون بإجر اء القياسات؛ حيث تم

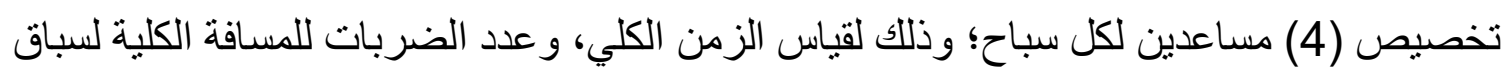
(50) متر في سباحة الزحف علي البطن، وزمن وعدد الضربات لمرحلة البداية 30متر الأولي، وزمن وعدد الضربات لمسافة 30 متر المتوسطة، وزمن وعدد الضربات لمرحلة النهاية 5 منر الأخيرة في سباق (50) متر لسباحة الزحف على علي البطن. - تم إجر اء القياسات على السباحين بواقع سباح كل مرة.

المتغيرات التي استخدمت في عملية التحليل:

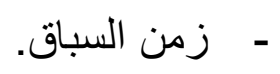

$$
\begin{array}{r}
- \\
-
\end{array}
$$




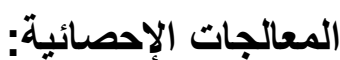

تم استخدام المعالجات الإحصائية المناسبة لطبيعة البحث، وهي كالآتي:

Mean

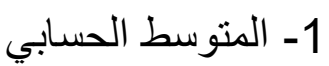

Median

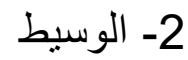

Standard deviation

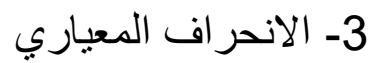

Skewness

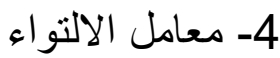

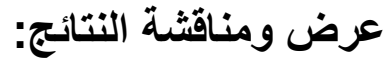

عرض النتائج التي توضح التساؤل الاول والذي ينص علي:

1- ما هي القيم الكمية لمتوسط متغيرات الأداء الفني (الأزمنة ـ طول الضربة ـ معدل الضربات - زمن

الضربة) خلال مرحلة المسافة الكلية لسباق (50) متر زحف على البطن؟

جدول (2)

المتوسط الحسابي والانحر اف المعياري ومعامل الالتواء للمتغيرات قيد البحث للمسافة الكلية لسباق (50) متر زحف علي البطن (ن=20)

\begin{tabular}{|c|c|c|c|c|}
\hline معامل الالتواء & الالنحياري اف & المتوسط الحسابي & وحدة القياس & المتغير ات \\
\hline-1.05 & 2.73 & 36.52 & ثانية & الزمن \\
\hline 0.83 & 1.99 & 26.55 & ضربة & عدد الضربات \\
\hline 0.64 & 0.14 & 1.89 & متر & طول الضربة \\
\hline 0.29 & 0.05 & 1.38 & ثانية & زمن الضربة \\
\hline 1.20 & 0.10 & 1.38 & متر / ثانية & معدل السرعة \\
\hline-0.20 & 1.53 & 43.64 & ضربة/ دقيقة & معدل الضربات \\
\hline
\end{tabular}

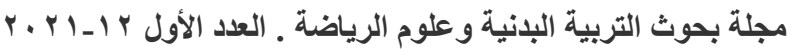


يتضح من الجدول (2) ان المتوسط الحسابي لزمن سباق (50) متر زحف علي البطن كان (16.52) ثانية وان

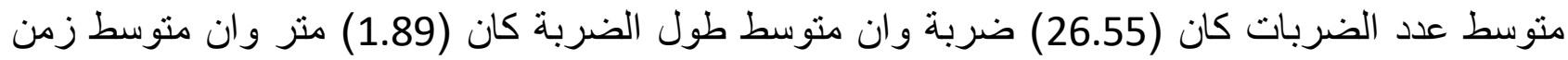

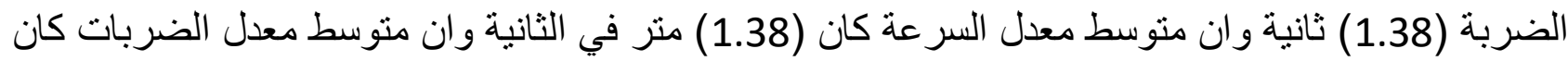
(43.64) ضربة في الدقيقة كما يتضح تفاوت استجابات السباحين علي متغير اتئ فئر الأداء. عرض النتائج التي توضح التساؤل الثاني والذي ينص علي: ما هي القيم الكمية لمتوسط متغيرات الأداء الفني (الأزمنة ـ طول الضربة ـ معدل الضربات - زمن الضربة) خلال مرحلة البداية 15 متر الاولي في سباق (50) متر زحف على البطن؟

\section{جدول (3)}

المتوسط الحسابي والانحراف المعياري ومعامل الالتواء للمتفيرات قيل البحث لمرحلة الباية 15 متر في سباق (50) متر زحف علي البطن (ن=20)

\begin{tabular}{|c|c|c|c|c|}
\hline معامل الالتو اء & المعياري الانحر & المتوسط الحسابي & وحدة القياس & المتغير ات \\
\hline-1.33 & 0.89 & 9.42 & ثانية & الزمن \\
\hline 0.35 & 0.85 & 6.10 & ضربة & عدد الضربات \\
\hline 0.06 & 0.36 & 2.51 & متر متر & طول الضربة \\
\hline 0.15 & 0.11 & 1.55 & ثانية & زمن الضربة \\
\hline 1.44 & 0.18 & 1.61 & متر / ثانية & معدل السر عة \\
\hline 0.05 & 2.80 & 38.81 & ضربة/ دقيقة & معدل الضربات \\
\hline
\end{tabular}

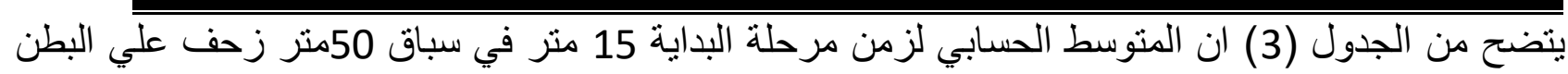

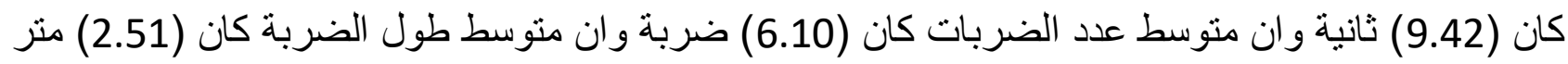
وان متوسط زمن الضربة (1.55) ثانية وان متوسط معدل السرعة كان (1.61) مثر في الثانية وان متوسط الثران

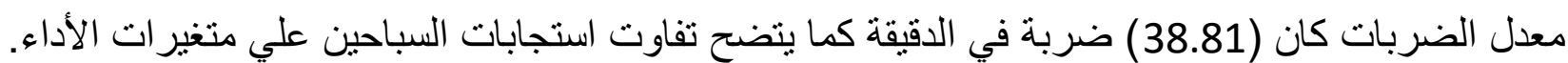


عرض النتائج التي توضح التساؤل الثالث والذي ينص علي:

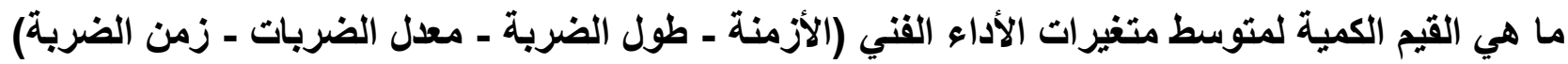
خلال مسافة 30 متر المتوسطة في سباق (50) متر زحف على البطن؟ الادئ

جدول (4)

المتوسط الحسابي والانحراف المعياري ومعامل الالتواء للمتفيرات قيد البحث لمسافة 30 متر المتوسطة لسباق (50) متر زحف على البطن (ن=20)

\begin{tabular}{|c|c|c|c|c|}
\hline معامل الالتو اء & المعياري & المنوسط الحسابي & وحدة القياس & المتغير ات \\
\hline-0.53 & 1.71 & 21.77 & ثانية & 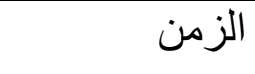 \\
\hline 0.83 & 1.08 & 16.30 & ضربة & عدد الضربات \\
\hline-0.67 & 0.12 & 1.85 & متر & طول الضربة \\
\hline 0.65 & 0.06 & 1.34 & ثانية & زمن الضربة \\
\hline 0.74 & 0.11 & 1.39 & منر / ثانية & معدل السر عة \\
\hline-0.54 & 2.08 & 45.02 & ضربة// دقيقة & معدل الضربات \\
\hline
\end{tabular}

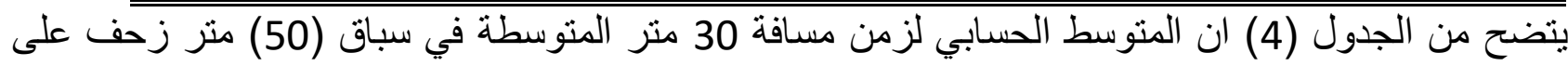

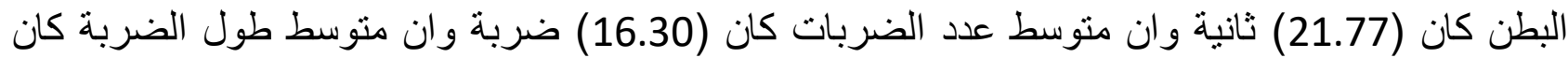

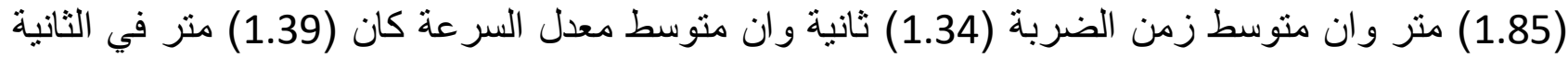
وان متوسط معدل الضربات كان (45.02) ضربة في الدقيقة كما يتضح تفاوت استجابات السباحين علي متغير ات ات الأداء. 
عرض النتائج التي توضح التساؤل الرابع والأي ينص علي:

ماهي القيم الكمية لمتوسط متغيرات الأداء القني (الأزمنة ـ طول الضربة ـ معدل الضربات ـ زمن الضربة) خلال مرحلة النهاية 5 متر الاخيرة في سباق (50) متر زحف على البطن؟

\section{جدول (5)}

المتوسط الحسابي والانحراف المعياري ومعامل الالتواء للمتغيرات قيد البحث لمرحلة النهاية 5 متر في

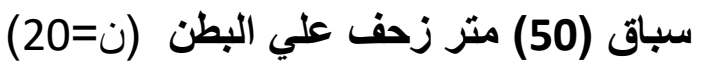

\begin{tabular}{|c|c|c|c|c|}
\hline معامل الالتواء & الالمعياري اف & المتوسط الحسابي & وحدة القياس & المتغير ات \\
\hline 0.45 & 0.34 & 5.34 & ثانية & الزمن \\
\hline 1.23 & 0.37 & 4.15 & ضربة & عدد الضربات \\
\hline-1.23 & 0.09 & 1.21 & متر & طول الضربة \\
\hline 0.19 & 0.07 & 1.29 & ثانية & زمن الضربة \\
\hline-0.30 & 0.06 & 0.94 & مثر / ثانية & معدل السر عة \\
\hline-0.03 & 2.67 & 46.63 & ضربة/ دقيقة & معدل الضربات \\
\hline
\end{tabular}

يتضح من الجدول (5) ان المتوسط الحسابي لمرحلة النهاية 5 منر الأخيرة في سباق 50مثر زحف علي البطن

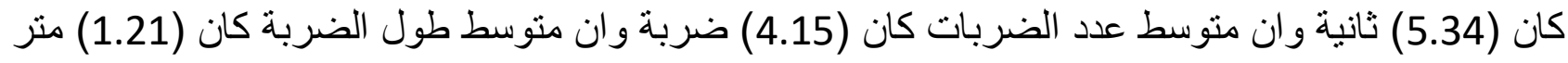
وان متوسط زمن الضربة (1.29) ثانية وان منوسط معدل السرعة كان (0.94) منر في الثانية وان منوسط معدل الضربات كان (46.63) ضربة في الدقيقة كما يتضح تفاوت استجابات السباحين علي متغير ات الأداء. مناقشة النتائج التي تفسر تساؤلات البحث :

يتضح من الجداول ارقام (2-3-4-5) ان المتوسط الحسابي لزمن سباق (50) متر زحف علي البطن كان (36.52) ثانية وان متوسط عدد الضربات كان (26.55) ضربة وان منوسط طول الضربة كان (1.89) منر وان متوسط زمن الضربة (1.38) ثانية وان منوسط معدل السرعة كان (1.38) منر في الثانية وان منوسط معدل الضربات كان (43.64) ضربة في الدقيقة. 
وان المتوسط الحسابي لزمن مرحلة البداية 15 مثر في سباق (50) متر زحف عل علي البطن كان (9.42) ثانية

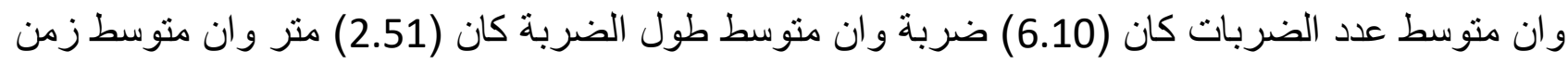

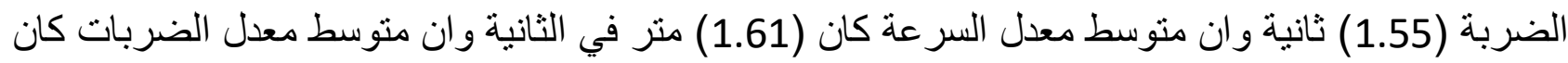

$$
\text { (38.81) ضربة في الدقيقة. }
$$

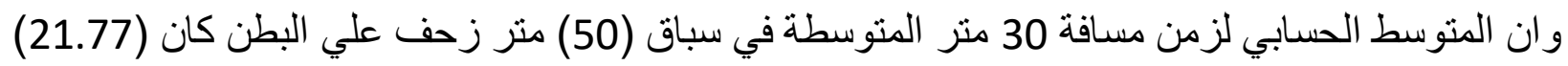

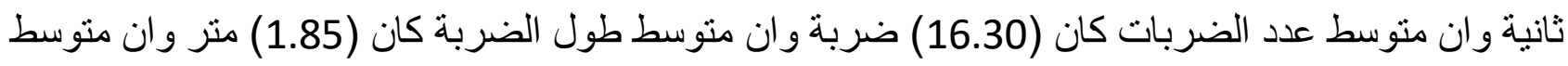

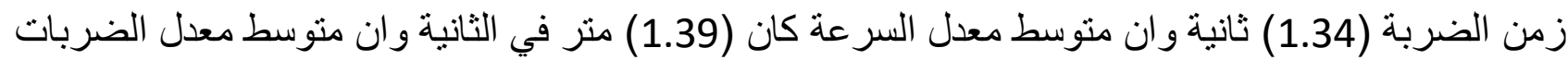
كان (45.02) ضربة في الدقيقة.

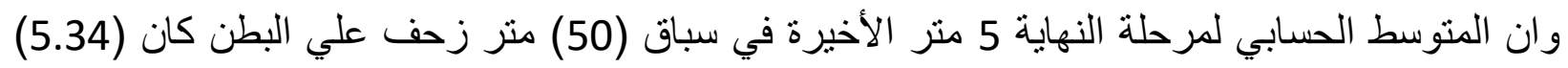

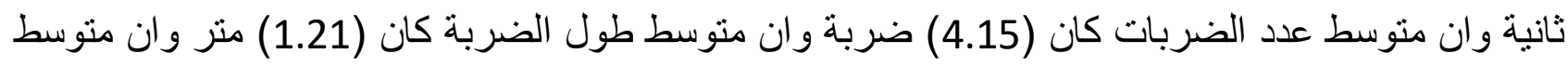

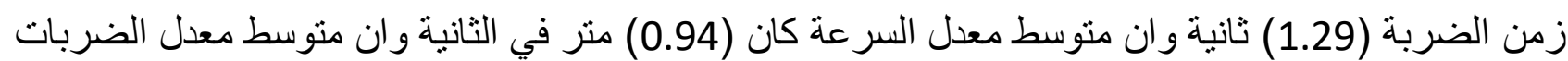
كان (46.63) ضربة في الدقيقة.

يتضح من العرض السابق ان اعلي قيمة لمتوسط طول الضربة كان في مرحلة البداية 15 متر الاولي حيث الطيث

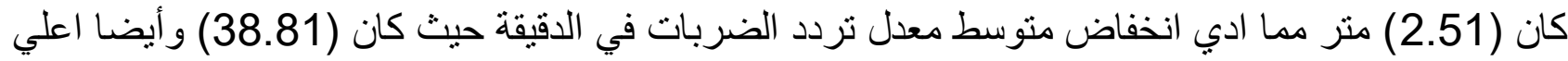
قيمة لمتوسط معدل السرعة كان في مرحلة البدء حيث كان (1.61) متر في الثنان فئنية.

ويتضح أيضا ان اقل قيمة لمتوسط طول الضربة كان في مرحلة النهاية 5 منر الأخيرة حيث كان (1.21)

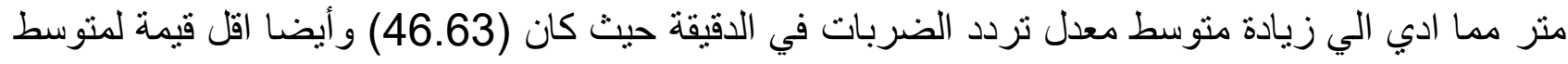
معدل السرعة كان في مرحلة النهاية حيث كان(0.94) منر في في الثردي الثانية.

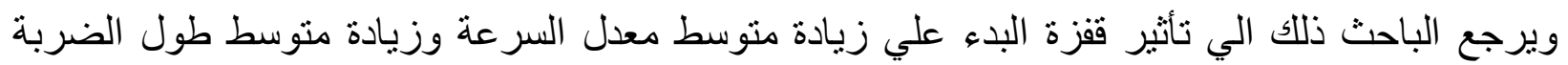

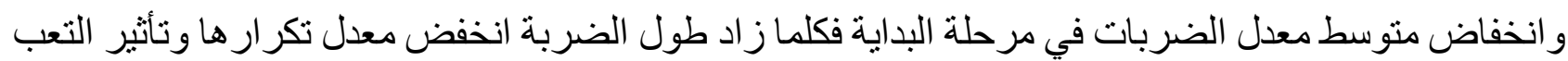

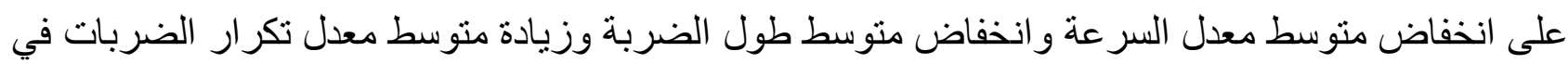

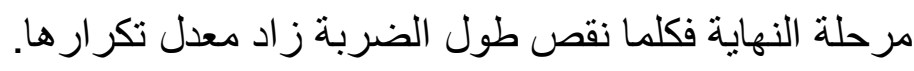

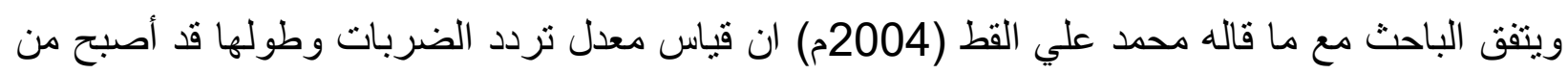

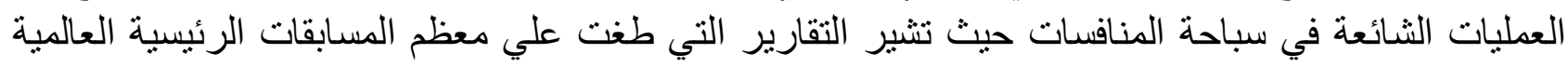

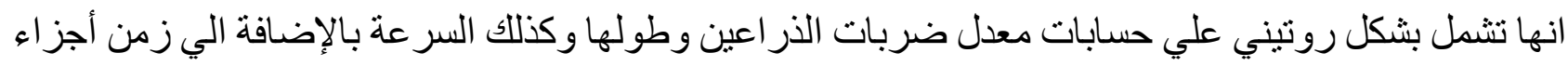

السباق. (146:13 (14)

ويتفق الباحث مع كلا من أست East (1970م) ، ميجاثشيتا Migashita (1975) (1975م) ، كونسلمارن (1977) Counsilman

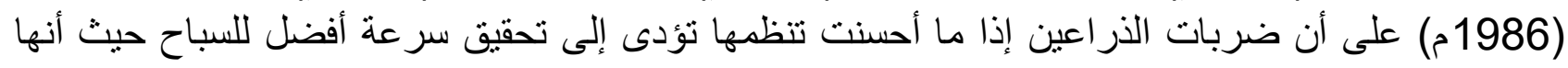


ترتبط بالقوى المحركة للجسم وتمده بنسبة تقدر بحوالى 70: 85 \% م من القوة الدافعة وهو ما يعادل تحقيق

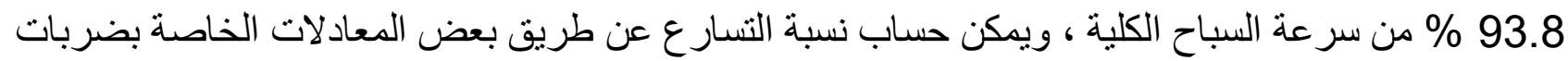

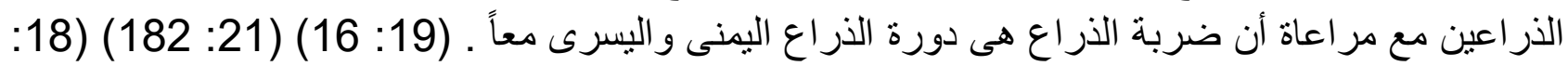
(56:3) (52:15) (16:17) (30

ويتفق الباحث مع أبو العلا عبد الفتاح حيث يبين انه ترجع أهمية التعرف علي معدل الضربات التهات انها تعطي

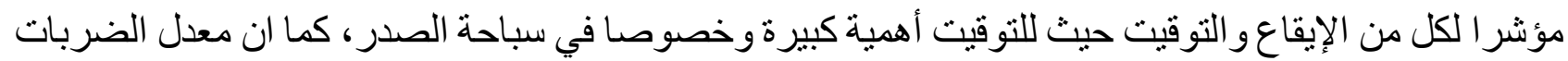

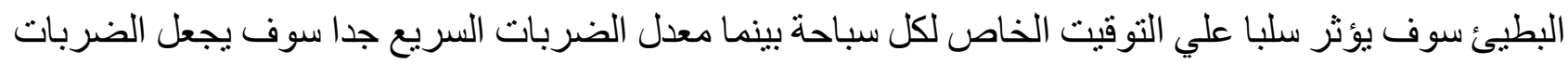
قصيرة وبالنالي يؤثر علي طول الضربة. (2:

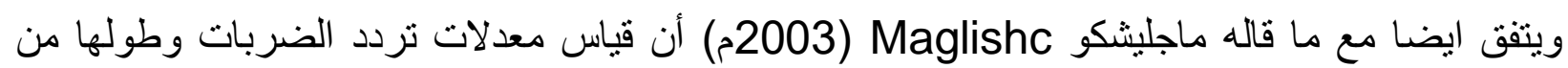

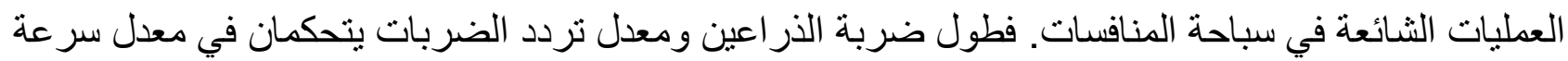

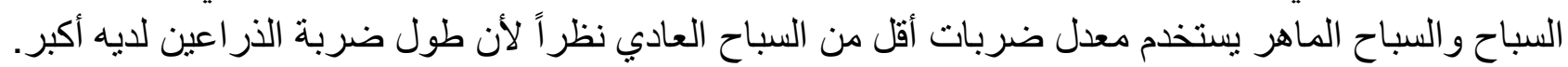

(695:20)

الاستنتاجات والتوصيات

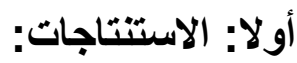

من خلال نتائج البحث وجد الباحث ان:

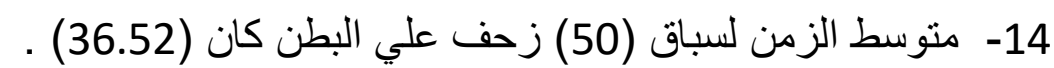

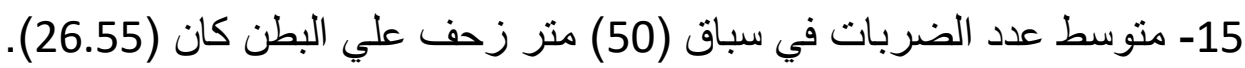

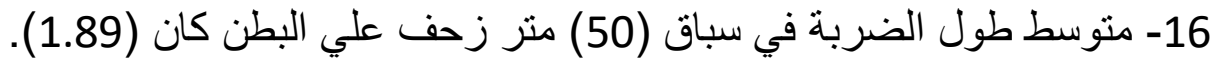

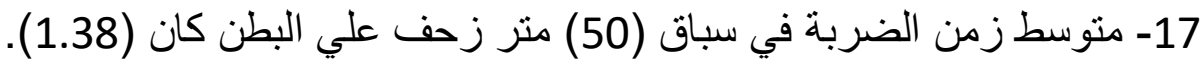

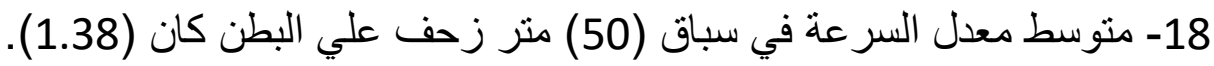

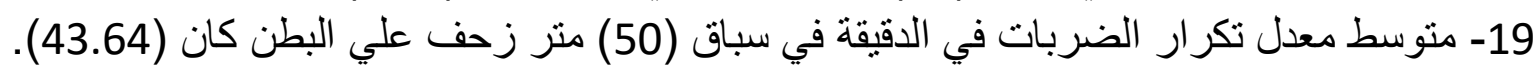

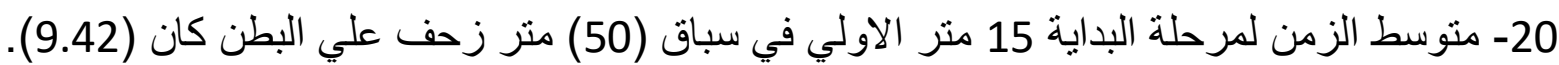

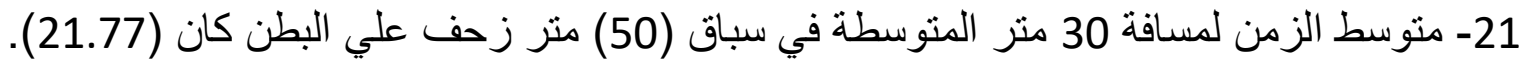

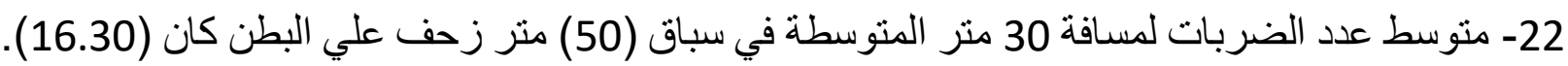

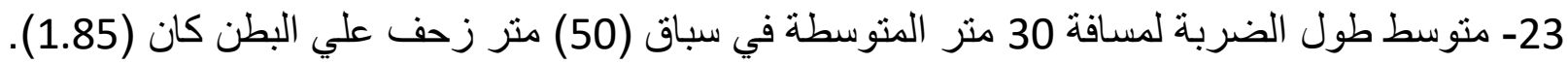

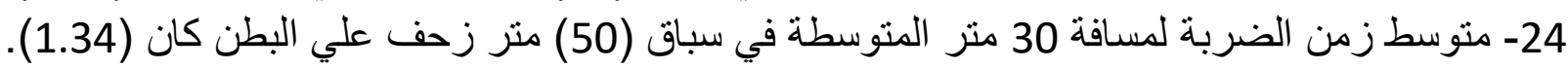

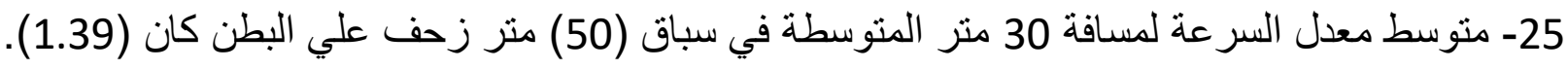

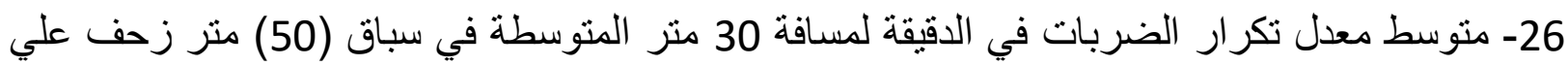

$$
\text { البطن كان (45.02) }
$$

27- منوسط الزمن لمرحلة النهاية 5 مثر الاخيرة في سباق (50) منر زحف علي البطن كان (5.34). 
1- ضرورة اهتمام المدربين خلال عملية التدريب بمحاولة حث السباحين على تثبيت شكل الأداء للضربة.

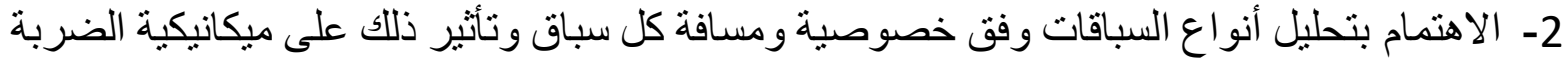

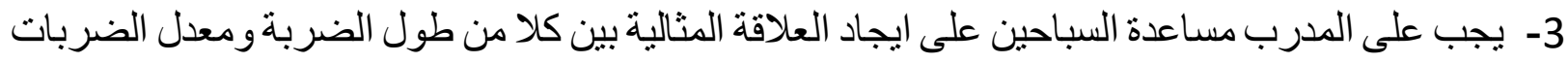

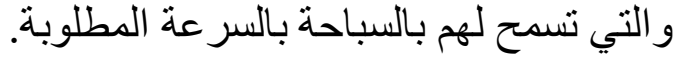

4- ضرورة اهتمام المدربين بتوجيه السباحين من خلال استخدام التغذية الرجعية المناسبة عن كيفية تحليل

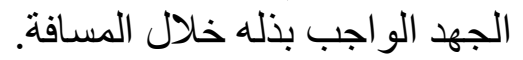
5- ضرورة اهتمام المدربين بإضافة وتقنين تدريبات خاصة خلال مر احل التدريب و التعليم موجهة نحو اكتساب السباح القدرة علي ضبط وتنظيم سر عة السباحة وفقا لخصائص طريقة السباحة ومسافة الأداء.

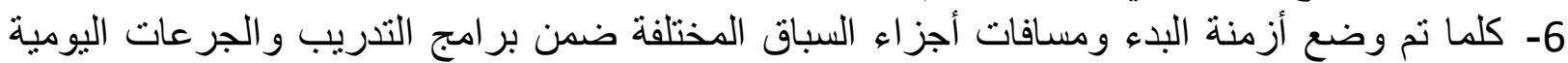
التدريبية كلما قلت تللك الأزمنة. 7- توجيه المدربين نحو تصميم تدريبات خاصة بمهار ات البدء و أجز اء السباق المختلفة خلال عملية التدريب

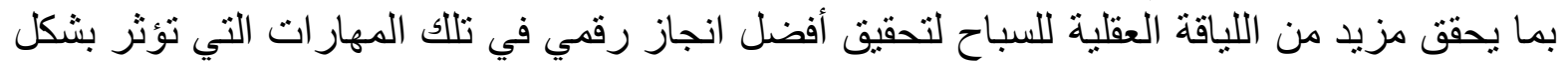
مباشر في المسنوي الرقمي للسباق. 
1. أبو العلا أحمد عبد الفتاح: تدريب السباحة للمستويات العليا، دار الفكر العربي، القاهرة،(1994م). 2. أبو العلا أحمد عبد القتاح، حازم حسين: الاتجاهات المعاصرة في تدريب السباحة، دار الفكر العربي

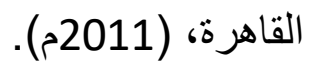

3. أحمد الحسيني: أثر السباحة بمعدلات مختلفة من السرعة على بعض النواحي الفسيولوجية والميكانيكية للسباحين، دار الوفاء لدنيا الطباعة و النشر، الإسكندرية، (2014م).

4. إسماعيل البيك: تحليل بيومتري لضربات الذر اعين في سباق الزحف علي البطن ،رسالة دكتوراة غير منشورة ، كلية التربية الرياضية للبنين، جامعة الإسكندرية، (1982م). 5. أمير محمد حسن سلمان سليمان: دراسة تحليلية لاستر اتيجيات تنظيم السرعة لسباقات ال 200م لدي سباحي المقدمة الناشئين من الجنسين، رسالة دكتوراه، كلية التربية الرياضية للبنين، جامعة حلوان،(2016م). 6. رائف محمد حسن احمد: دراسة تحليلية لايناميكية الأداء في سباحة400م حرة، رسالة دكتور اه، كلية التربية الرياضية للبنين، جامعة حلوان، (2006م). 7. طلحة حسام الدين، وفاء صلا الدين ، مصطفي كاظم: الموسوعة العلمية في التدريب الرياضي ، القاهرة،مركز الكتاب للنشر،ط1 ، الجزء الثاني، (1997م). 8. عادل عبد البصير: الميكانيكا الحيوية والتكامل بين النظريةو التطبيق في المجال الرياضي ، مركز الكتاب للنشر ، القاهرة ، (1998م). 9. عصام حلمي: اتجاهات حديثة في تدريب السباحة، دار المعارف، الإسكندرية(1997م). 10. محمد السيد شحاته الطنطاوي: در اسة تحليلية لديناميكية الاداء في سباحة200 م ظهر، رسالة ماجستير، كلية التربية الرياضية للبنين، جامعة بنها، (2014م). 
11. محمد صبري عمر: هيدروديناميكا الأداء فى السباحة، طه، منثأة المعارف، الإسكندرية،(2001م). 12. محمد عبد الحميد طـه: بناء نموذج رياضي لبعض مكونات الأداء الفني لاى سباحي المسافات

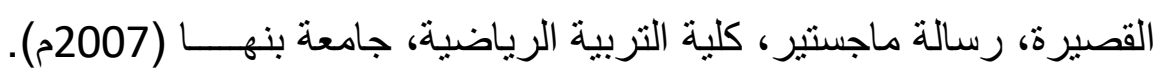
13. محمد علي القط: استراتيجية السباق فى السباحة، المركز العربى للنشر، القاهرة، (2004م). 14. محمد محمود عرابي علي: دراسة تحليلية لقيم مؤشر ات الضربة ومقاومة التعب وعلاقتهم بالمستوي

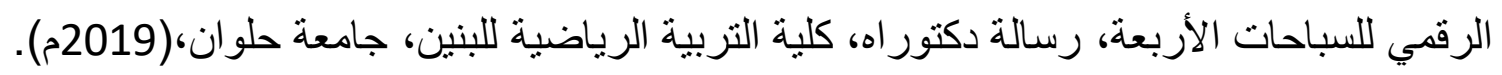

15. محمود عبد الفتاح عنان: دراسة تحليلية للسر عة فى سباحةّ100م حرة لاى سباحى البطولة الأفريقية بالقاهرة، المجلد العلمى الر ابع لدراسات البحوث للتربية الرياضية، كلية التربية الرياضية للبنين، جامعة ليطية

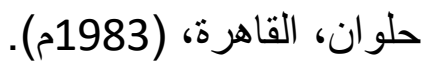
16. محمود عبد الفتاح عنان: سباحة المنافسات، مكتبة إبر اهيم حلبي، الرياض (1989م).

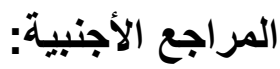

17. Bucher, C.A: The influence of the leg Kick and the arm stroke on the total speed during the crawl stroke the $2^{\text {nd }}$, ed., International sympsion on bio mechanics in swimming university park pres., 1978.

18. Counsilman,: Comptitive swimming, Manual for coaches and swimmers, councilman, Co, Blooming-Ton, 1977.

19. East, D: Swimming an analysis for stroke frequency stork length and performance, G. of heath phy. Sical eduction and recreation no, 2, New,Aland, 1970.

20. Maglischo E.W: (2003) Swimming faster the essential ref. ence ontechnique Training and program design, human kinatics U.S.A. 
21. Migya Shita, $\mathbf{M}$,: Arm. Action in the crawl stroke $2^{\text {nd }}$ ed., International sympsion, on bio Mechanics in swimming university park 1975.

22. Schibert, $\mathbf{M}$,: Competitive swimming Techniques for champions, time I.N.C. 1990. 